\title{
El carisma de la efigie en el libro impreso ${ }^{1}$
}

\section{The Charisma of Effigies in Printed Books}

\author{
Ana Elena GonZÁLEZ TREviÑo \\ Facultad de Filosofía y Letras \\ Universidad NACIONAL AutónOMA DE MÉXICO \\ México
}

\begin{abstract}
Resumen
Desde los bustos de mármol de la Antigüedad que custodian sus libros en las bibliotecas, la práctica de incluir retratos autorales al lado de las obras literarias sigue vigente. Con el advenimiento del libro impreso, el uso de la efigie cobró mayor importancia hasta convertirse en un paratexto a veces obligado para la interpretación de la obra literaria. Los retratos autorales se basan en procesos de ethopoiesis, o de construcción de carácter, que obedecen a los valores imperantes en el contexto en el que se producen. Algunos modelos típicos de la persona autoral son el poeta laureado, el genio romántico, la monja letrada, la cortesana y la autora exótica; una de las poses adoptadas con mayor frecuencia es la pose melancólica. En este artículo se presentan algunos ejemplos significativos.
\end{abstract}

Palabras clave: retrato, representación autoral, historia del libro, autoría y género, cuerpo autoral, paratexto

\begin{abstract}
The practice of including authorial portraits along with literary works may be found already in the marble busts of classical Antiquity. With the advent of the printed book, the use of this authorial marker acquired greater importance to
\end{abstract}

\footnotetext{
${ }^{1}$ El carisma es una "especial capacidad de algunas personas para atraer o fascinar"; una efigie es una "imagen o representación de una persona" (Real Academia Española, s. f.) y, aunque con una connotación más amplia, es un sinónimo de "retrato". Efigie y retrato se utilizan aquí de manera intercambiable para enriquecer la connotación, como se explica más adelante por su relación con la numismática. El libro impreso alude a la práctica de impresión occidental posterior a Gutenberg. La primera sección de este artículo toma ejemplos anteriores a manera de introducción. De ninguna manera se pretende que este breve ensayo sea exhaustivo, sino que simplemente ofrece tipologías sugerentes para investigaciones subsecuentes. Los múltiples retratos aludidos en el texto se encuentran en línea. Al final se presentan algunos enlaces significativos.
} 
the extent that it is sometimes an indispensable paratext for literary interpretation. Authorial portraits are based on processes of ethopoiesis, or the construction of character, circumscribed by prevailing values. A few typical models for the construction of the authorial persona are the following: the poet laureate, the romantic genius, the erudite nun, the courtesan, the exotic author; one of the most common poses is the melancholic pose. This article surveys a few meaningful examples.

Keywords: portrait, authorial representation, history of the book, authorship and gender, authorial body, paratext

La función autoral, entendida como un campo de la estructura libresca, tiene una muy significativa encarnación en el retrato impreso, pues si bien dicho retrato no es por mucho indispensable, sí constituye, después del nombre, una forma consagrada para asentar una paternidad textual que busca reproducir un régimen discursivo de filiación por medio de la contigüidad visual. De él se derivan varios significados dignos de considerarse. Uno de ellos, acaso el más inmediato, es un sentido de garantía que acredita y legitima el contenido del libro en la medida en que satisface la necesidad de designar a un responsable, alguien que rinda cuentas o que literalmente dé la cara para validar al texto. A lo largo de los siglos se han gestado distintos convencionalismos para la representación del ícono autoral, y aquí se esbozarán algunos de ellos.

Ningún texto puede prescindir de una cierta materialidad, si bien ésta siempre está determinada por la tecnología disponible en el momento histórico de su producción. Dicha materialidad puede portar o no huellas de procedencia textual, es decir, la indicación de quién concibió y escribió lo que ahí se consigna. El formato del libro impreso tiene casi siempre un espacio destinado para ese fin, al tiempo que permite albergar tanto la obra en sí como una efigie autoral de tamaño y calidad proporcionales; cuando la hay, dicha efigie pone de manifiesto la coexistencia de signos lingüísticos y visuales que enlazan la experiencia de la lectura con la génesis del fenómeno literario a través de la imagen de quien lo produjo. Entre los signos visuales, el retrato sobresale como sucedáneo del autor por excelencia pues se basa en procesos de representación mimética gráfica, auxiliares en la construcción de la autoridad textual en tanto que invocan al garante de su calidad y que además es su "progenitor". Junto con el nombre del autor, los signos visuales que se articulan en el retrato se apoyan en códigos culturales compartidos que se han ido construyendo a todo lo largo de la historia del libro, y que conjugan el medio escrito con el medio plástico.

El claro predominio de autores varones en la actividad literaria a lo largo de los siglos ha ocasionado que el lenguaje utilizado para describir la relación entre el autor y la obra sea eminentemente masculino, al grado de que en los relatos de creación no interviene ningún agente femenino, pues la musa etérea o su equivalente desempeña un papel pasivo (Gilbert y Gubar, 2012; Goldberg, 1994: 308). 
Dicho lenguaje, no obstante, sí puede echar mano de la experiencia reproductiva femenina para describir el proceso creador. En ciertos contextos es lugar común que los escritores varones desplieguen imágenes de "partos" para consolidar su ethos autoral. Como "concepciones" abstractas, los textos en sí se han descrito como la progenie del autor $\mathrm{y}$, hasta cierto punto, se reciben y comercializan como si fueran portadores de un linaje (MacFaul, 2010: 36; Seelig, 1996). De ahí el hábito de establecer paternidades en cuanto a género, temática y formato, por ejemplo, para conformar una historia literaria. ${ }^{2}$

Debe hacerse notar que la autoría femenina tiende a constituir una suerte de anomalía en los cánones literarios, misma que se ve reflejada en los códigos que rigen la representación gráfica de las escritoras, sobre todo en etapas tempranas de la industria editorial. Más aún, quienes han dado cuenta de la autoría femenina han debido ajustar las narrativas de creatividad y generación literarias, aun cuando hacerlo pudiera parecer un despropósito, pues las funciones de musa y escritora son tradicionalmente incompatibles, en tanto que la musa posibilita la creación, mas no la ejerce (Vallejo, 2007: 81-2). Así la crítica literaria feminista en un momento dado transforma la "ansiedad de la influencia" que subyace al canon literario en la "ansiedad de la autoría" femenina por la transgresión genérica que supuestamente implica (Gilbert y Gubar, 2012). Sin que sea su enfoque exclusivo, en este estudio se incluyen algunos ejemplos de retratos de escritoras que ponen en evidencia estas tensiones ideológicas.

En el acto de lectura se establece una actividad dialógica que resulta evocadora de la presencia humana: recordemos a Quevedo y su afán de "conversar con los difuntos", es decir, de leer obras de autores de otros tiempos. En el traslado del pensamiento a la escritura podrá desaparecer el cuerpo del autor, mas no su palabra: ésta resuena como un rasgo de humanidad en un objeto inanimado con características propias. Por ello resulta provocador señalar lo obvio: los libros impresos, que durante siglos y hasta hace no mucho se consideraron el vehículo ideal para los textos, están diseñados para el cuerpo humano, sí, pero no guardan ningún parecido físico con él. Un retrato, sin embargo, en tanto que representación bidimensional, es compatible con la materialidad del libro - con la página impresa, para ser exactos- y se ha utilizado repetidamente, entre otras cosas, para reforzar la sensación de que el acto de lectura implica entablar un tipo de relación con otro ser humano, que además de un puente intelectual ofrece, a través de la representación de su corporeidad, un enlace tangible para comulgar con él. La ausencia física del autor se ve suplida por la presencia simbólica de su efigie. Así pues, en el momento en que la tecnología y el diseño permiten la inclusión del retrato del autor junto con el texto que escribió, aquel cumple en primera instancia la misión de garantizar la legitimidad de su vástago, como un padre que reconoce

\footnotetext{
${ }^{2}$ El hecho de que las autoras mujeres también describan sus escritos con este lenguaje no significa que el uso de la metáfora de parte de autores varones deje de ser una apropiación de una experiencia femenina.
} 
a su hijo ante un registro civil; y, en segundo lugar, logra humanizar al libro, es decir, establecer una base de humanidad común entre la actividad de la escritura y la actividad lectora, entre el autor y el lector, puesto que echa a andar mecanismos de identificación a nivel icónico (Alexander, 2008; Jones, 2013: 163).

Los retratos autorales, como se verá, están fuertemente codificados y responden a distintos proyectos culturales de ethopoiesis, o fabricación del carácter. Como tales, están inscritos en procesos históricos, a veces muy marcados, que con frecuencia buscan vincularse con proyectos del pasado que sentaron precedentes. Cabe insistir, sin embargo, en que no sólo son invención del autor mismo: aunque materializados por el editor, el diseñador y el artista (pintor, grabador y posteriormente, fotógrafo), son el producto colectivo de una cultura entera que los necesita justo como aparecen retratados, y por eso resulta más o menos fácil tipificarlos. Desde el poeta laureado hasta el novelista intelectual, veremos un muestrario de las posibilidades de representación y caracterización que encierran los proyectos de imagen autoral.

El retrato, al igual que otros paratextos, se lee en un espacio hermenéutico distinto del que engloba la obra en sí, especialmente si se trata de una obra de ficción, pues ostensiblemente se presenta bajo un régimen de verdad con transparencia semiótica o referencial en donde el autor se acerca al lector en su identidad común. Por más caracterizado que aparezca aquél en su retrato según el ethos acordado - tácita o expresamente- con el artista y el editor, representarlo con cuerpo y atributos humanos para enmarcar su obra abstracta de algún modo lo vuelve más asequible y manejable, para bien o para mal. Dirige y encauza la intención dialógica del lector en su réplica, no siempre silenciosa, al tiempo que constituye un objeto de interpretación por sí mismo que se descifra en conjunción con la obra, sí, pero también en conjunción con el universo extratextual. De los autores retratados, algunos tienen verdaderas trayectorias iconográficas a lo largo de su carrera que, por muy paratextual que sea su condición, resultan necesarias para la interpretación de sus obras sólo por el hecho de acompañarlas (Kuitert, 2011: 369).

La tradición de presentar el texto con el retrato del autor es casi tan antigua como el concepto de autoridad; en la Antigüedad clásica, se hicieron bustos en mármol de los grandes autores, como por ejemplo Platón y Aristóteles, para emular en su efigie la inmortalidad de su obra. Resulta sugerente el carácter sintético de estos bustos que resumen la persona autoral en un segmento del cuerpo, el más identificable, el más memorable tal vez, pero no por ello menos parcial: la cabeza, la singularidad del rostro y el gesto como la fuente original de donde procede su obra. Los bustos clásicos se instalaban en las bibliotecas, cerca de sus libros (o rollos), como un recordatorio de la identidad y de la humanidad de los autores, pero también como custodios de sus obras, a la manera de las esfinges o las gárgolas. La narrativa de la permanencia del arte (el texto, la imagen) por encima de la corta vida humana se traduce en una práctica cultural que se expresa por antonomasia a través de las efigies en mármol, ya que sus códigos están fuertemente 
dictados por la naturaleza física de esta sustancia pétrea. El carácter mimético de las representaciones refuerza la idea de que la identidad perdura en el ícono, tanto más si la materialidad de éste es duradera en comparación con el efímero cuerpo humano (Woodall, 1997: 11).

Al mismo tiempo, en el caso de los autores inmortalizados en piedra, la relativa inmutabilidad de ésta surte un efecto de anquilosamiento que con los años hace que se olvide el sentido de humanidad que antes aportaba, y en vez de humanizar, la efigie del autor se convierte en un recordatorio amenazante de la estatura paterna que arroja una sombra no siempre protectora sobre el lector (y el autor potencial, o el lector como autor potencial), y que desemboca en la creación de cánones y panteones como los que conocemos hoy en día. Aunque fue en la Antigüedad clásica cuando más se practicó esta forma de representación, ella fue retomada en la modernidad, época en que la autoría literaria buscó emular la grandeza percibida en los antiguos, en un afán de lograr una fama póstuma análoga. Los bustos modernos reproducen una forma artística del pasado para inscribirse en los anales de la inmortalidad, y poco a poco constituirse a su vez en autoridades, sin descontar el hecho de que su efigie ya tiene otras posibilidades de reproducción en los retratos al óleo y los retratos impresos.

En ese sentido, la Edad Media puede ser más modesta y recatada. El arte del retrato se circunscribía por lo general a representar efigies monárquicas, aristocráticas o hagiográficas (a veces combinadas), en objetos tales como monedas, medallas y túmulos mortuorios. Los ejemplos hallados en libros o cuadros también privilegiaban a estos personajes; los retratos autorales no abundan en este periodo justo porque el concepto de autor era distinto, no era tan medular como hoy en día, y no necesariamente se requería la representación de su rostro. Cierto es que en esta época se generaliza la forma del libro que conocemos en la actualidad (incluso antes de que se inventara la imprenta de tipos móviles), pero, aunque los manuscritos medievales a veces incluyen retratos de autores pintados a mano, éstos no necesariamente ocupan un lugar preeminente en relación con las demás ilustraciones.

$\mathrm{Al}$ igual que en la tradición hagiográfica el santo se reconoce por sus atributos particulares, las representaciones del autor medieval podían asimilar atributos de sus obras para ser identificados con éstas, como por ejemplo el hoy célebre retrato de Geoffrey Chaucer (1343-1400) en el manuscrito Ellesmere de los Cuentos de Canterbury (MS EL 26 C 9, en la biblioteca Huntington, cerca de Los Ángeles, California). En él aparece Chaucer caracterizado como un peregrino más, montado en su caballo. Su retrato no adorna el frontispicio del libro, sino que está semi oculto en el margen del capítulo 17 (folio 153v.); sólo se halla cuando finalmente llega su turno de contar una historia. Su cuento, de los menos notables de la colección, tampoco ocupa el último lugar — que pudiera verse como honroso en un sentido más irónico - sino que le siguen otros relatos. Queda claro que en la cultura en que se produjo dicho manuscrito no resultaba prioritaria la imagen del 
autor, a diferencia, por ejemplo, de la apropiación contemporánea de esta obra que llevó a cabo la Universidad de Long Island en una edición facsimilar, en donde el folio con el retrato de Chaucer se convierte en el frontispicio del libro de manera forzada, para adecuarse a nuestros cánones (Fowler, 2017).

Con el advenimiento de la imprenta, la técnica del grabado se volvió clave para la representación del rostro autoral. La incuestionable superioridad del libro impreso para acelerar la circulación de textos, en comparación con el códice o libro manuscrito, otorgó a los autores un carisma sólo comparable al del perfil imperial que adornaba las monedas de dinero circulante: el autor se convierte en una verdadera divisa del conocimiento y del arte, o de lo que vale una nación. El hecho de que el autor fuera considerado un personaje digno de representación como lo habían sido antes sólo gobernantes, aristócratas y santos, habla ya de una cultura del reconocimiento literario o artístico, a menudo nacionalista, que se ensalza a sí misma al engrandecer a sus autores, en un escenario internacional en donde se compite por la hegemonía.

Uno de los primeros autores en aprovechar esta tecnología revolucionaria fue Erasmo de Rotterdam (1466-1536), de quien se conservan diversos retratos pintados o grabados hechos por artistas de gran renombre como Hans Holbein y Alberto Durero. Los retratos de Erasmo, según algunos, formaban parte de sus estrategias de autopromoción y de la construcción de su carácter de autoridad intelectual en la modernidad incipiente (Jardine, 1995: 60). Él y otros humanistas, cuyos retratos aparecieron en los primeros libros impresos de la modernidad temprana, nos proporcionan claves importantes acerca del uso que se pretendía dar al libro en esta nueva modalidad. Es a partir del siglo XV que el ícono autoral se convierte en un verdadero paratexto, en el sentido de que funciona como un entorno textual cuyo significado modifica la exégesis literaria y cuyos orígenes son complejos y diversos (Genette, 1989: 11-12). El uso que se le dio al retrato en esta época contribuyó a sentar las bases del concepto moderno de autoría, en tanto que creó una asociación indisoluble entre obra y autor a través de su nombre y de su imagen. Esta asociación tendría consecuencias importantes, en la medida en que la obra impresa se identificaría no sólo como progenie del autor, sino también como el fruto tangible de un trabajo eminentemente intelectual que de otra manera sería invisible y no cuantificable. El poder plasmar este trabajo en un objeto concreto, vendible y reproducible, conduciría a nociones como la de derechos de autor, en la que el creador del texto obtiene un beneficio económico por su escritura al identificarse con el nombre y, en este caso, con el retrato que acompaña la obra. Y aunque esto no sucedería sino hasta el siglo XVIII, las bases de dicho mecanismo se sentaron por lo menos dos siglos antes.

En los albores de la cultura impresa, el retrato no sólo humaniza la creación libresca, sino que se convierte en un poderoso refuerzo de la autoridad de quien escribe, y hace del libro una fuente de conocimiento rodeada del aura de la incontestabilidad, sobre todo cuando se emplea con fines educativos. En terminología 
contemporánea, se puede decir que hay ya un afán de diseño de imagen personal tendiente a la construcción de un capital cultural, cuya perdurabilidad no necesariamente anticiparon sus creadores de manera suficiente. Publicar libros impresos en el siglo XV y principios del XVI es también un ejercicio derivado de un proyecto de autor en donde todavía se perciben las raíces clericales de los autores medievales: Erasmo, Juan Luis Vives, Tomás Moro y muchos otros humanistas se hacen retratar como hombres de letras, vestidos de negro, circunspectos, rodeados de libros y a menudo en el acto mismo de escribir.

Estos casos funcionaban, en gran medida, como modelos a seguir para los jóvenes que asistían a las escuelas humanistas. De ahí que, tratándose de un ámbito escolar, no nos extrañe encontrar algunos ejemplares cuyos dueños no resistieron la tentación de profanar el ícono académico, como en dos retratos del mismo Erasmo, rescatados recientemente de uno de sus libros, que aparecen tachonados y desfigurados, acaso por algún escolar descontento (Guerrero, 2013). Y es que todo monumento iconográfico puede desatar una reacción iconoclasta: la destrucción del ícono escenifica la supresión o muerte del autor y de lo que su obra representa. El retrato autoral puede despertar emociones que lo convierten también en un blanco simbólico, alineado con la tradición de la infamia, que es la damnatio memoriae, hallada por ejemplo en los retratos de líderes depuestos o delincuentes buscados por la ley, ambos considerados dignos del escarnio público (Prusac y Kolrud, 2014: 43). En sentido opuesto, sin embargo, por el hecho mismo de dar la cara, de respaldar su creación con el cuño de su rostro, se da un movimiento en el que la estabilización icónica produce en el público lector un efecto idólatra, efecto que los vendedores de libros han sabido explotar muy bien, pues constituye una divisa a veces muy redituable. Baste apuntar aquí el fenómeno que se dio más adelante de agregar retratos en retrospectiva a obras que originalmente se publicaron sin ellos para refrendar y potenciar su vigencia (Howe, 2008: 467).

En los siglos siguientes, la experiencia editorial para la construcción de la figura del autor se enriqueció, y los proyectos ethopoieicos se complejizaron. Con el humanismo se rescataron no sólo las obras de la Antigüedad sino además sus valores. De ahí que una de las retóricas favoritas para la manufactura de una figura autoral distinta del erudito hombre de letras esté tomada del pasado clásico en un intento de legitimar las obras contemporáneas: se trata del poeta laureado. Vigente, por supuesto, desde tiempos de Petrarca (quien fuera coronado con laureles en el siglo XIV y para quien a su vez Homero y Virgilio serían modelos fundamentales), cuando la figura del poeta laureado llega al libro impreso, empero, su función es distinta, pues las circunstancias han cambiado con respecto a la Antigüedad con la que buscan identificarse. Por ejemplo, en la singular colección reunida en el Libro de descripción de verdaderos retratos de ilustres y memorables varones (c. 1599) de Francisco Pacheco (1544-1599), Fernando de Herrera, Gutierre de Cetina, Rodrigo Caro, Francisco de Quevedo y otros poetas aparecen 
coronados de laureles. En este periodo dicha corona se convierte en un atributo iconográfico indicativo de la profesión poética sin necesidad de referente real. (La obra de Pacheco es un rico compendio de retratística en general y del culto de la fama, pero para fines de este ensayo sólo hago notar la recurrencia de los laureles.)

Atributo de Apolo, perseguidor de Dafne, el laurel también se usó en la Antigüedad para coronar a los atletas vencedores en distintas contiendas deportivas dedicadas al dios solar. De ahí que su simbología vincule la actividad poética con el heroísmo, significación que en la modernidad temprana se traduce en un lazo entre la cultura libresca y la masculinidad heroica. El poeta, sobre todo el poeta épico, hace aportaciones esenciales para la construcción de identidades colectivas a través de la representación exaltada de la historia. En el momento en que se establece una asociación semiótica entre el poeta laureado y la gloria nacional, el autor participa en cierta medida de la gloria y del heró́smo guerrero, tradicionalmente masculino, que encomia en sus escritos. No será él quien haya librado las batallas, pero su destreza para plasmarlas a través de la palabra basta para que su persona sea celebrada en su propio presente. Esta masculinización de la actividad poética es una de las razones por las cuales la posibilidad de una autoría femenina para la poesía épica (y por ende, para la poesía en general) pareciera un contrasentido, al grado de que fue concebida apenas recientemente, y de existir, sólo lo hizo de manera oculta o marginal, jamás laureada (Downes, 2010). En todo caso, la poesía épica cede gradualmente su lugar a formas literarias distanciadas del contexto del combate, aunque perduren estos lazos de género.

En el siglo XVII, lejos parecen estar — y lo estarán, más o menos hasta el siglo XIX - los afanes de escribir un gran poema épico para celebrar hazañas heroicas, puntales del sentido de identidad de una nación, y forjadoras de la idea del poeta como un personaje valioso para la comunidad. La poesía épica en todo caso explora otros terrenos, como los relatos bíblicos en el caso de Milton (1608-1674), poeta de gran ambición que sin embargo quedó ubicado en el lado perdedor de una contienda histórica (la Guerra Civil inglesa). Jamás sería coronado con los laureles que tanto anhelaba, y en cambio sí sus detractores políticos, como John Dryden (1631-1700). A pesar del aire anacrónico, los poetas de la modernidad a menudo se siguieron representando en sus retratos impresos con alusiones a los lauros de la Antigüedad, con una dimensión hiperbólica destinada a actualizarlos con respecto a los valores épicos del pasado, pero para un momento histórico y un espacio geográfico en donde la función autoral se empieza a vincular más con otras virtudes, tales como el ingenio verbal y la originalidad.

En esta época, algunas de las pocas autoras cuya obra se publicó se identificaron no con el acto de escritura, sino, emulando a Platón al referirse a Safo, con la musa inspiradora en una metonimia delatora de los valores imperantes. Anne Bradstreet (1612-1672) y Sor Juana Inés de la Cruz (1651-1695), por mencionar sólo dos ejemplos, fueron apodadas por igual como "la décima musa", cada una en su contexto. Asociadas ambas con el Continente Americano, surten 
un efecto perturbador en el canon por su doble otredad dentro del universo de la cultura libresca. La inclusión de retratos femeninos para reafirmar la autoría femenina representó un dilema cultural que trazaba una delgada línea entre la imagen pública obligada y la virtud — en principio, opuesta — de la modestia (Van Deinsen, 2019: 283).

En un retrato de 1692 hallado en una recopilación de las obras de Sor Juana, Mercurio y Minerva la adornan con una corona de laureles, mientras la Fama pregona su grandeza a Oriente y Occidente no con una, sino con dos trompetas. La corona, no obstante, está alejada de la cabeza de Sor Juana por partida doble: primero, por un marco ovalado en donde hay una leyenda con su adscripción conventual, el Convento de San Jerónimo en México — la palabra México queda cuidadosamente centrada - y su nombre, Madre Juana Inés de la Cruz; en segundo lugar, por su toca monjil que hace las veces del pelo o la peluca en los retratos de autores varones de la misma época (Escamilla, 2009). ¿Acaso esta separación pueda leerse como señal de su virginidad para las cosas del mundo, como se destaca en la leyenda en latín al calce? ¿Acaso se trata de un decoro que procura resguardar su femineidad de los peligros mundanos de la publicación? ¿O acaso está así enmarcada como un énfasis en su lejanía geográfica del centro europeo en una época en la que se creía que nada bueno podía salir de América? En general, en los retratos de Sor Juana, el parecido entre la imagen y la persona pudiera no existir, sobre todo en el que nos ocupa, que es de calidad mediocre, pero esto carece de importancia: el objetivo principal era simplemente representar a una mujer, monja y escritora, que escribe desde México.

Entre los dos polos que van de la virgen a la cortesana, el fenómeno de la autoría femenina desestabiliza los mecanismos de representación asociados a valores masculinos, aun cuando no escapa de ellos. Pocas décadas después de Sor Juana estuvo activa la autora inglesa Eliza Haywood (1693-1756). En su época los retratos de los autores se usaban ya de manera generalizada en los frontispicios, y funcionaban como un sustituto portátil y en miniatura del autor ausente, un fetiche privado que el comprador adquiría junto con el texto o de manera independiente, donde podía volcar su devoción o su repudio. Los grabados en cobre, sin embargo, eran caros y se reservaban para la obra de autores consagrados, por lo que se convirtieron en una marca distintiva de estatus editorial. Por ese motivo, cuando en la década de 1720 se publicaron con un retrato los poemas de Eliza Haywood, actriz, dramaturga y autora de poesía erótica y tórridos romances novelados, la reacción por parte de los poetas establecidos fue de infinito desprecio. De por sí se pensaba que tanto actrices como autoras eran "mujeres públicas" (Van Deinsen, 2019: 305); ahora bien, exponer su rostro y su cuerpo al escrutinio generalizado, junto con la "pretensión" de autoridad, resultó demasiado para figuras de autoridad tan centrales como Alexander Pope, quien la ridiculiza despiadadamente en su Dunciada, haciendo una anatomía satírica de su cuerpo según el retrato publicado: 
Fair as before her works she stands confess'd, In flow'r'd brocade by bounteous Kirkall dress'd.

Pearls on her neck, and roses in her hair, And her fore-buttocks to the navel bare.

The Goddes [sic] then: "Who best can send on high

"The salient spout, fair-streaming to the sky;

His be yon Juno of majestic size,

With cow-like Udders and with ox-like eyes." (Barchas, 2003: 22-23)

En castellano:

Bella frente a sus obras se confiesa,

en florido brocado liberalmente vestida por Kirkall,

perlas en el cuello y rosas en el pelo,

con las nalgas delanteras luciendo hasta el ombligo.

La diosa [es decir, la musa] entonces dijo, "Quien mejor pueda lanzar

el surtidor [¿de su obra?] como torrente al cielo,

suya será esta Juno de majestuosa talla,

con ojos de buey y con tetas de vaca."

Salvo por el collar de perlas que parece haber sido un añadido de Pope, se cree que la descripción sí parece corresponder al retrato en cuestión. Es una imagen típica de su época en la que Haywood aparece retratada de medio cuerpo con el rostro de tres cuartos, con un marco ovalado, coronado por un moño de listón satinado. Su gesto es serio, aunque con una levísima sonrisa; lleva un peinado conservador con una discreta flor arriba de la oreja derecha. El problema está, a juzgar por la reacción de Pope, en el carácter seductor del escote, algo que nunca se encuentra en un retrato masculino de la época, y que a Pope le parece inaceptable.

Aunque esta representación obedece a convencionalismos de la época y no a un designio intencional de Haywood, Pope la culpa a ella personalmente, junto con el artista Kirkal (una atribución, por cierto, equivocada), que cumple más o menos la función de un modisto bajo la mirada satírica de este autor (Barchas, 2003: 22). Los insultos de Pope entran dentro de la categoría más baja de la argumentación, que en retórica sería ad hominem, aunque aquí, con mayor justeza, sería ad feminam, pues el blanco de su burla son los atributos físicos femeninos de Haywood según quedaron plasmados en el retrato impreso. La falta de pudor que percibe en la autora se ofrece en la parodia de Pope como un trofeo ridículo para quien resulte vencedor en un concurso masculino de naturaleza fálica y eyaculatoria. No alude ni siquiera tangencialmente a la obra de Haywood: lo que para él es el descaro de la publicación femenina basta para constituir una afrenta imperdonable.

Es evidente que el ethos autoral en este caso está basado en lineamientos con resabios clásicos (la composición recuerda las efigies de musas o diosas grecolatinas), pero por la naturaleza erótica de la obra, se relaciona también con la tradición 
del retrato íntimo, como la imagen secreta que se guarda en un camafeo: el marco ovalado incluso aparenta estar sujeto por un lazo y un broche o alfiler femenino. Tiene afinidad con los retratos de amantes típicos de la Restauración inglesa (heredados de la moda francesa), y que se usaban también para ilustrar las obras de autores tan respetables como Chaucer, Shakespeare y Milton. Se alinea también con los retratos de jóvenes enamorados y amantes desdeñados del Renacimiento - varones todos - en los que el desaliño de la vestimenta era indicio de su padecimiento amoroso. La connotación del retrato de Haywood es ya un anuncio del contenido del libro, poesía amatoria, con la diferencia de que la autora hace también las veces de figurín, y su propia semi desnudez se ofrece como publicidad, en lugar de la desnudez de una modelo anónima (Spedding, 2011).

Si Sor Juana fue apodada "la décima musa" y "el fénix de México", Eliza Haywood recibiría el mote de "la gran árbitra de la pasión" ("The Great Arbitress of Passion"), y así las caracterizarían sus editores. La dificultad reside tal vez en la combinación entre un cuerpo voluptuoso e incitante, y el rostro reconocible de una autora que en última instancia buscaba legitimarse por los frutos de su pensamiento, lo que resulta en un diseño de imagen contradictorio. En la gran mayoría de los retratos autorales, como se verá, se procura suprimir o reducir a su mínima expresión la corporeidad para subrayar con el gesto y la mirada las cualidades intelectuales de la persona autoral, sin importar la calidad de la obra; aquí sucede lo contrario.

Lo que se torna evidente es que hay una manipulación deliberada de la representación autoral con fines cada vez más declaradamente comerciales, que experimentan y explotan las posibilidades gráficas del libro impreso. En el siglo XVIII, sobre todo en lo que se refiere al género novelesco, hubo una gran cantidad de experimentos gráficos y visuales, al grado que el libro como objeto material rivalizaba con su contenido en cuanto a creatividad y originalidad (Barchas, 2003: 25). La exuberancia visual de las primeras novelas ha recuperado vigencia en el contexto de los estudios literarios, a partir de la revaloración del aspecto material de las ediciones originales.

Un ejemplo célebre de esta manipulación es el retrato que adorna la primera edición de Los viajes de Gulliver (1726) de Jonathan Swift (1667-1745). En una labor de complicidad creativa entre autor, editor y artista, motivados en parte por miedo a la censura y a las represalias políticas, en el frontispicio del libro, en el campo reservado para el nombre del autor y con mayúsculas compactas, se lee "Lemuel Gulliver" y, a la izquierda, con el mismo realismo que cualquier retrato de la época, aparece la figura de un hombre con un marco ovalado en el que se lee "Capitán Lemuel Gulliver, de Redriff, a sus 58 años". Poco importaba que Gulliver fuera un personaje imaginario: su retrato (que no guarda ningún parecido con Swift), así como los mapas que se incluyeron en las primeras ediciones, funcionan como paratextos que buscaban darle a la obra estatuto de verdad, como una simple explotación de los recursos ficcionales implícitos en el formato del libro.

Este montaje por un lado busca insertar la obra en el género de la literatura de viajes, muy popular en la época, para disfrazar el hecho de que en realidad constituye 
una mordaz sátira política. El hombre del retrato, además de no corresponder a una persona real, no es coherente tampoco con el personaje Gulliver, puesto que éste acaba sus viajes loco y desposeído en un establo, y su edad, según los datos proporcionados dentro de la narración, tendría que ser de 65 y no 58 años. Esta última cifra es en realidad un guiño que apunta a la identidad del verdadero autor de la obra, Jonathan Swift, cuya edad sí era 58 años cuando ésta se publicó. El libro causó sensación desde un principio y, aunque muchos lo interpretarían de inmediato como una sátira política por demás explosiva, muy pocos sabrían leer las sutiles pistas que revelaban quién era en realidad el autor (Barchas, 2003: 31). Insertar el retrato dentro del universo de la obra constituye una transgresión de los convencionalismos formales referidos a los estatutos de verdad y ficción con fines satíricos, y sin duda abre nuevas posibilidades de articulación entre obra, autor y lectores.

Otro ejemplo notable es el de la obra de la esclava-poeta Phillis Wheatley (1753-1784), publicada en 1773, cuando comenzaba a difundirse más el movimiento abolicionista. La representación de esta joven escritora revela las tensiones culturales que caracterizaban el mundo transatlántico en el siglo XVIII: tensiones entre el genio romántico y la idea de "barbarie"; de originalidad e imitación; de expresión y de domesticación; de natura y cultura. Las posibilidades de ficcionalización del retrato fueron aprovechadas por los promotores de Wheatley, quien fue comprada como esclava desde la infancia, y que sólo con la autorización de sus dueños (portadores originales también del apellido Wheatley) pudo legitimar su autoría ante un público que oscilaba entre el sistema de mecenazgo, la cultura de salón y la creciente comercialización del libro. En ese sentido, este retrato de Wheatley, aunque producto de la Ilustración, prepara el terreno para el romanticismo.

La poeta está representada con un marco similar al de Sor Juana, en donde se resalta su posición social, pues reza "Phillis Wheatley, sirvienta negra del Sr. John Wheatley, de Boston". Está sentada en una silla ante una pequeña mesa donde hay un librito, un tintero y un papel sobre el cual escribe con una larga pluma de ganso, mientras apoya la cabeza en la mano izquierda con gesto pensativo y mira, de perfil, a la lejanía. Viste a la usanza de la época y según su posición social, con gorro, cuello y delantal blancos, sobre un vestido de un tono menos claro. Su gesto y su mirada buscan subrayar el carácter pensante de la autora, pero el artista indica también sus particularidades físicas a través de la técnica del grabado: aunque el cabello queda oculto bajo el gorro, se aprecia el tono oscuro de su piel y sus rasgos africanos. Estos detalles que en primera instancia pueden considerarse el simple resultado de una estética de intención realista, en el contexto libresco de la época constituyen una curiosidad, casi una anomalía, y por ello resultan decisivos para la interpretación de la obra. Su poesía sería apreciada sólo a la luz de su otredad física y social, pues se le describió como una "bárbara inculta" que de manera inexplicable poseía "genio poético". Paradójicamente, ambas interpretaciones tuvieron el efecto de reforzarse la una a la otra. Hasta la fecha, el retrato de Phillis Wheatley marca un hito en la historia de la construcción de la autoría negra (Zuck, 2010). 
Para el siglo XIX el retrato autoral se había estabilizado como mecanismo de mercadeo, fruto de la industrialización definitiva de la literatura a gran escala. En este periodo, se promovía la idea de que los lectores formaran relaciones íntimas, si bien imaginarias, con los autores, así como la lectura de la obra como expresión autobiográfica. Los retratos de escritores, sobre todo a partir de la incorporación de técnicas fotográficas al proceso editorial, reforzaban la idea de la presencia auténtica del autor, y el hecho de que éste diera la cara de alguna manera aumentaba la credibilidad de sus escritos (North, 2012). Empero, el efecto no para ahí, sino que se construye un verdadero carisma, es decir, una fascinación por la figura autoral que se expresa, entre otras, en lealtad comercial. Adicionalmente, existe un estrecho paralelismo entre el desarrollo de las técnicas publicitarias y la inclusión de retratos en los libros. La práctica de incluir catálogos editoriales y otros anuncios en un mismo tomo propició la creatividad tipográfica, el diseño editorial y la identidad de marca junto con las representaciones del rostro humano (Curtis, 2019).

El retrato como paratexto constituye un espacio cultural en donde tiene lugar una transacción entre el lector, el editor y el autor, siempre en torno a la obra. Aun así, en el siglo XIX el retrato autoral conoce un auge tal que llega a independizarse del texto literario en el formato de tarjetas pequeñas o medianas de gran circulación. La experiencia de "conocer" al autor a través de su efigie sintetiza e incluso consigue obviar el conocimiento de la obra, pero evidencia también una sociedad en la que la literatura goza de un estatus privilegiado. En el siglo XIX los retratos autorales se coleccionaban como se coleccionan hoy en día los retratos de futbolistas o estrellas de cine, en un acto moderno de culto a la celebridad. Un caso ejemplar es el de Hans Christian Andersen (1805-1875) cuya estampa llegó a venderse más de 20 mil veces, según se relata en una conocida anécdota (Kuitert, 2011: 363). La fascinación que ejercieron los retratos de autores en este periodo se vio reforzada por la técnica de reproducción fotográfica, cuyo realismo parecía ofrecer una aproximación al genio literario sin precedentes. Se creía que la fotografía, a diferencia de otras técnicas, ofrecía un acercamiento al espíritu mismo del autor (Kuitert, 2011: 355, 361), lo cual tuvo como resultado un efecto idólatra que encumbró a los autores por encima de los simples mortales.

Paradójicamente, esto conllevaba también un efecto democratizador, pues se ponía en evidencia, como ya se dijo, la humanidad y corporeidad del autor: frágil, falible, mortal (Kuitert, 2011: 365). El público lector quería saber qué aspecto físico tenía el autor de lo que leía, cómo vestía, cómo se peinaba, cuáles eran sus gestos, y todo lo que se pudiera leer en la imagen como una síntesis biográfica en donde se entretiene la mirada y se proyectan las fantasías. Sería ingenuo creer que este fenómeno no alimentó la vanidad de los autores, cuya fama creció como nunca antes. En esta época, la pose preferida por el público debía mostrar algo de tristeza y sufrimiento para satisfacer justamente las ilusiones de los lectores de que los genios también sufrían. En algunos casos se llegaron a utilizar máscaras mortuorias para acompañar las obras. Autores como Charles Baudelaire (1821-1867) y Paul Verlaine (1844-1896) 
llevaron al extremo esta moda con poses y actitudes inusuales, mismas que luego se tipificaron y fueron imitadas por muchos más. Baudelaire, por ejemplo, se hizo retratar con la mirada agresiva y la ropa desaliñada, y Verlaine, tumbado en el sillón de un café (Kuitert, 2011: 368). Ellos contribuyeron a alimentar el mito del autor excéntrico a través del performance fotográfico de su autoría.

Las mujeres, a pesar de que muchas de ellas habían logrado subsistir como escritoras profesionales por lo menos desde el siglo XVIII, se seguían percibiendo como una anomalía que necesitaba justificación. Por ello se buscó demostrar una y otra vez la compatibilidad entre la actividad literaria y la vida doméstica, para indicar que no por escribir se transgredía el ideal cultural de la femineidad. Una de las poses más comunes de esta época es la de la escritora sentada delante de su escritorio privado, sin salir del espacio femenino del hogar. No se dejó de explotar, empero, el toque más o menos escandaloso que acompañaba a las publicaciones de las mujeres y que tanto había contribuido a aumentar las ventas de libros en el pasado, aunque ahora se daba en el contexto de la intimidad: el retrato podía ir acompañado de algún relato biográfico que revelara algún secreto de la vida privada de la autora. Las imágenes de escritoras en ambientes significativos dan cuenta de la creciente mercantilización de la fama literaria, en particular del aspecto físico de las autoras, creando estereotipos en cuanto a edad, actitud, belleza, moda, posición social y más. Hay quien ha llegado al grado de afirmar que dichas imágenes contribuyeron al desprestigio de las escritoras incluso hasta el siglo siguiente (Hawkins y Ives, 2012: 7).

En el siglo XX la persona autoral ya es una mercancía probada; a través de la fotografía, los procesos ethopoieicos se asemejan cada vez más al diseño de marcas comerciales para insertarse en un mercado literario extremadamente dinámico. Un caso ejemplar es el de Samuel Beckett (1906-1989), cuyo rostro fotografiado se convirtió en un sello inconfundible de un nuevo tipo de genialidad literaria, y en cuyo cuidadoso diseño se perfilan nuevos objetivos. Por ejemplo, uno de los más célebres retratos del autor, que data de 1973, es una fotografía en blanco y negro donde aparece su rostro surcado de unas arrugas casi inverosímiles de tan profundas, como revelando que la vida misma ha escrito duros renglones en la piel de su semblante; pero el sujeto ha logrado retener la mirada indomable, penetrante y alerta. La cabeza está aislada en un fondo totalmente negro, sin cuello, sin escenografía, buscando crear a la persona autoral como una conciencia creativa aislada de todo, una cabeza flotante que desafía la mortalidad humana.

Para la creación de la poderosa imagen pública de Beckett se tuvo que reunir un conjunto de expertos en distintas disciplinas tales como iluminación, diseño de vestuario, dirección de escena, fotografía, sin excluir por supuesto la complicidad de Beckett mismo, cuya habilidad para administrar su persona autoral no ha pasado inadvertida (Dilks, 2006: 162). Estamos ya en presencia de un ícono cultural en su máxima expresión, con identidad comercial bien delimitada en el contexto del mundo literario y que en definitiva funciona como un filtro para la interpretación de la obra. 
Por sorprendente que resulte, en lo que se refiere a las mujeres hoy en día se siguen explotando códigos que se rigen por los prejuicios discriminatorios del pasado. En enero del año 2000 se publicó White Teeth [Dientes blancos] de Zadie Smith (1975), autora británica cuya madre nació en Jamaica y dos de cuyos hermanos son raperos profesionales, datos relevantes para entender el proceso ethopoieico detrás de sus retratos promocionales. Se han hecho estudios de cómo se hizo la mercadotecnia de White Teeth, y queda claro que conceptos tales como "autenticidad" y "minoría" suelen condicionar las expectativas (¿prejuicios, estereotipos raciales?) que el público ya de por sí tiene acerca de un cierto grupo "étnico" (Jakubiak, 2008: 202). Se ha argumentado que el concepto mismo de "autenticidad" es un constructo concebido por voces hegemónicas para condicionar el tipo de consumo que se espera. La representación de Zadie Smith en sus fotografias tiende a subrayar sutilmente su otredad, al tiempo que su belleza — que bien puede leerse como una mismidad - no deja de ser aprovechada por los editores y comentada por los críticos, quienes han descrito su persona como "stunning" [despampanante] y como "a stylist's dream" [el sueño de un estilista]: el hecho de que a menudo aparezca en las fotografías con turbante ha sido muy celebrado porque acentúa su carácter "exótico". Si esto beneficia o perjudica la lectura de su obra, será tema de debate (Jakubiak, 2008: 211). Lo cierto es que el señuelo editorial busca sacar provecho de la imagen de la autora, acentuando esta caracterización, aunque ostensiblemente no sea así.

En el polo opuesto de la anomalía se encuentra la norma, que no deja de estar impregnada de sus propias paradojas representacionales. Uno de los ethos autorales más socorridos, sobre todo desde que la fotografía empezó a sustituir al grabado, de alguna manera sintetiza tres antecesores - el poeta laureado, el genio romántico y el erudito humanista - y está prefigurado en el famoso ángel de la melancolía de Alberto Durero. La pose melancólica en la que el sujeto apoya la cabeza en una o ambas manos, ya con el realismo de detalles físicos que brinda esta tecnología, promueve la idea de que el autor es un ser especial, que se sabe incomprendido, pero que no puede evitar su genialidad. Algunos inclinados hacia la izquierda, otros hacia la derecha, mirando a la cámara o a la lejanía, serios o sonrientes; decenas de autores aparecen con la pose melancólica en sus libros y/o en objetos promocionales como carteles y volantes. Dicha pose está pensada para funcionar solamente en la singularidad que supone el modelo de autor que impera en el presente, singularidad que además refuerza la dicotomía mente-cuerpo, y que busca vincular la obra más a aquélla que a éste. La aparente concesión que la mente hace al cuerpo al darse permiso de posar, resulta no ser sino una estrategia más para fortalecer el puente entre autor, editor, fotógrafo, diseñador y, finalmente, lector.

Este modelo parece no hacer distinciones de género, edad, raza o posición social, ni tampoco si se trata de alta cultura o cultura popular. Si se comparan retratos de hombres y mujeres, jóvenes y viejos, eruditos o comerciales, se verá que en todos hay predilección por esta pose, y todos parecen hacer concesiones a la 
vanidad, a la supuestamente despreciada belleza superficial. Y es que los retratos, que tanto ayudan a la venta de libros - y acaso por eso mismo - no pueden escapar a una lectura que los conecta con los valores mundanos, aunque el ideal intelectual busque desvincularse de la corporeidad y de la esfera terrenal.

Los libros, como espero haber dejado en claro, no los "escribe" nada más el autor o la autora: él o ella deben dejarse escribir (moldear, normalizar o "exotizar") por quienes los van a vender y comprar. El gesto de la cabeza apoyada en la mano - a veces francamente señalando lo alto de la cabeza como el sitio privilegiado para la creación y que en teoría está por encima de las apariencias- representa por un lado una concesión a la (para muchos, chocante) necesidad de ser retratado; pero la displicencia de la pose melancólica permite expresar a la vez un mínimo de resistencia a esta práctica cultural. No obstante, la resistencia a la representación es justo lo que se esperaría de un autor hoy en día, por lo que, paradójicamente, cumple con los requisitos del estereotipo autoral. El retrato impreso parece decir con un cierto desdén: "sí, soy genial; y qué."

\section{Referencias bibliográficas}

AleXANDER, Jeffrey C. (2008). "Iconic Experience in Art and Life: Surface/Depth Beginning with Giacometti's Standing Woman". Theory, Culture \& Society, 25(5), 1-19. https://doi.org/10.1177/0263276408095213

ARREDONDO, María Soledad. (2009). Paratextos en la literatura española: siglos XVI-XVIII. Madrid: Casa de Velázquez.

BAKer, Malcolm. (2014). Fame and Friendship: Pope, Roubiliac and the Portrait Bust. Londres: Paul Holberton.

BARChas, Janine. (2003). Graphic Design, Print Culture and the Eighteenth-Century Novel. Cambridge: Cambridge University Press.

CHARTIER, Roger. (1994). The Order of Books: Readers, Authors, and Libraries in Europe between the Fourteenth and Eighteenth Centuries (Lydia G. Cochrane, Trad.). Cambridge: Polity.

CurTIS, Gerard. (2019). Visual Words: Art and the Material Book in Victorian England. Londres: Routledge.

DiLKs, Stephen John. (2006). "Portraits of Beckett as a Famous Writer". Journal of Modern Literature, 29(4), 161-188.

Downes, Jeremy. (2010). The Female Homer: An Exploration of Female Epic Poetry. Newark: University of Delaware Press.

EnEnKel, Karl A. E. (2011). “The Author's Portrait as Reader's Guidance: The Case of Francis Petrarch". En Celeste Brusati, Karl A. E. Enenkel y Walter Melion (Eds.), The Authority of the Word: Reflecting on Image and Text in Northern Europe. Boston: Brill. 151-180. 
EsCAMILLA, Iván. (2009). "El lifting de Sor Juana”. Cultura UNAM. Diario digital. Artes e historia de México. México: UNAM. Consultado el 30 de diciembre de 2019 http://www.arts-history.mx/blog/index.php/component/k2/item/434el-lifting-de-sor-juana.

Fowler, Alastair. (2017). The Mind of the Book: Pictorial Title-Pages. Oxford: Oxford University Press.

GenetTe, Gérard. (1989). Palimpsestos. La literatura en segundo grado. Madrid: Taurus.

GilBerT, Susan, y Gubar, Sandra. (2012). "Infection in the Sentence: The Woman Writer and the Anxiety of Authorship". En Robyn Warhol-Down y Diane Price Herald (Eds.), Feminism: An Anthology of Literary Theory and Criticism. Rutgers University Press. 21-32.

GoldBERG, Jonathan. (1994). Queering the Renaissance. Durham, Carolina del Norte: Duke University Press.

Guerrero, Manuel. (2013). Joan Fontcuberta, Deletrix. Barcelona: Ediciones Poligrafía.

HaWkins, Ann R., y IVES, Maura C. (Eds). (2012). Women Writers and the Artifacts of Celebrity in the Long Nineteenth Century. Farnham, Surrey: Ashgate.

HowE, Sarah. (2008). "The Authority of Presence: The Development of the English Author Portrait, 1500-1640". The Papers of the Bibliographical Society of America, 102(4), 465-499.

JAKUBIAK, Katarzyna. (2008). "Simulated Optimism: The International Marketing of White Teeth". En Tracey Lorraine Walters (Ed.), Zadie Smith: Critical Essays. Nueva York: Peter Lang. 201-218.

JARDINE, Lisa. (1995). Erasmus, Man of Letters: The Construction of Charisma in Print. Princeton: Princeton University Press.

Jones, Amelia. (2013). Seeing Differently: A History and Theory of Identification and the Visual Arts. Nueva York: Routledge.

KuiterT, Lisa. (2011). "Reading the Body: Author's Portraits and Their Significance for the Nineteenth-Century Reading Public". En J. Arianne Baggerman, Rudolf M. Dekker y Michael James Mascuch (Eds.), Controlling Time and Shaping the Self. Leiden: Brill.

MacFaul, Tom. (2010). Poetry and Paternity in Renaissance England: Sidney, Spenser, Shakespeare. Cambridge: Cambridge University Press.

NorTH, Julian. (2012). "Picturing Nineteenth-Century Authors: from Austen to Brontë". Victorian Studies Centre Blog, Universidad de Leicester. Consultado el 13 de marzo de 2020 en https:/victorianstudiescentre.wordpress.com/ 2012/11/24/picturing-victorian-authors-by-dr-julian-north/

PrUSAC, Marina, y KolRUD, Kristiane. (2014). Iconoclasm from Antiquity to Modernity. Farnham, Surrey: Ashgate.

REAL ACADEMIa ESPAÑola. (s.f.). Diccionario de la lengua española. https://dle.rae.es/ 
SeElig, Sharon Cadman. (1996). Generating Texts: The Progeny of SeventeenthCentury Prose. Charlottesville: University of Virginia Press.

Shillingsburg, Peter L. (2011). Resisting Texts: Authority and Submission in Constructions of Meaning. Ann Arbor: University of Michigan Press.

Spedding, Patrick. (2011). “James Parmentier Portrait of Eliza Haywood”. En Patrick Spedding. Research Notes [Blog]. Consultado el 30 de diciembre de 2014 de http://patrickspedding.blogspot.mx/2011/10/james-parmentier-portrait-of-eliza.html

VAllejo, Catharina. (2007). "From Muse to Poet: Paratextual Practices of Women Poets in Cuba at the End of the Nineteenth-Century". Decimonónica: Revista de producción cultural hispánica decimonónica, 4(1), 80-93.

VAn Deinsen, Lieke. (2019). "Visualising Female Authorship. Author Portraits and the Representation of Female Literary Authority in the Eighteenth-Century Dutch Republic". Quaerendo, 49(4), 283-314. https://doi.org/10.1163/ 15700690-12341449

Woodall, Joanna. (1997). Portraiture: Facing the Subject. Manchester: Manchester University Press.

ZucK, Rochelle Rainieri. (2010). "Poetic Economies: Phillis Wheatley and the Production of the Black Artist in the Early Atlantic World". Ethnic Studies Review, 33(2), 143-68.

\section{Enlaces adicionales}

PACHECO, Francisco. (1599). Libro de descripción de verdaderos retratos de ilustres y memorables varones. Disponible en: http:/www.cervantesvirtual.com/ portales/juan_de_la_cueva/imagenes_personajes/imagen/imagenes_personajes_06_libro_de_descripcion_de_verdaderos_retratos_de_illustres_y_memorables_varones_texto_impreso_4/

Wheatley, Phillis (s. f.). Poems on various subjects. Disponible en: https://www. loc.gov/exhibits/treasures/images/tlc0395.jpg

SOR JuANA, musa décima. (1689). Inundación castálida de la única poetisa, musa décima... Disponible en: http://www.cervantesvirtual.com/portales/sor_juana_ines_de_la_cruz/obra-visor/inundacion-castalida-de-la-unica-poetisamusa-decima-soror-juana-ines-de-la-cruz-que-en-varios-metros-idiomas-yestilos-fertiliza-varios-assumptos-con-elegantes-sutiles-claros-ingeniososutiles-versos-para-ensenanza-recreo-y-admiracion--0/html/ f6d8e785-dc2c-4e67-8aa4-e1061f39d2ff_5.htm

Haywood, Eliza. (s. f.). National Portrait Gallery. Disponible en: https://www. npg.org.uk/collections/search/person/mp59078/eliza-haywood-nee-fowler Gulliver, Lemuel. (s. f.). British Library. Disponible en: https://www.bl.uk/collection-items/first-edition-of-gullivers-travels-1726 